\title{
Practice and Innovations of Inclusive Education at School
}

\author{
Larysa V. Kozibroda ${ }^{1}$, Oksana P. Kruhlyk ${ }^{2}$, Larysa S. Zhuravlova³ ${ }^{3}$ Svitlana V. Chupakhina ${ }^{4}$ \& Olena M. \\ Verzhihovska ${ }^{5}$ \\ ${ }^{1}$ Department of Physical Education, Institute of the Humanities and Social Sciences, Lviv Polytechnic National \\ University, Lviv, Ukraine \\ ${ }^{2}$ Department of Deaf Pedagogy and Deaf Psychology named after M. D. Yarmachenko, Faculty of Special and \\ Inclusive Education, National Pedagogical Dragomanov University, Kyiv, Ukraine \\ ${ }^{3}$ Department of Preschool Education and Social Work, Educational and Scientific Institute of Social-Pedagogical and \\ Artistic Education, Bohdan Khmelnytsky Melitopol State Pedagogical University, Melitopol, Ukraine \\ ${ }^{4}$ Department of Theory and Methods of Nursery and Special Education, Faculty of Pedagogy, Vasyl Stefanyk \\ Precarpathian National University, Ivano-Frankivsk, Ukraine \\ ${ }^{5}$ Department of Psychological-Medical-Pedagogical Foundations of Correctional Work, Faculty of Correctional and \\ Social Pedagogy and Psychology Kamianets-Podilskyi National Ivan Ohienko University, Kamianets-Podilskyi, \\ Ukraine
}

Correspondence: Larysa V. Kozibroda, Lviv Polytechnic National University, 12 Stepana Bandery str., Lviv, 79000, Ukraine.

Received: June 10, 2020

Accepted: August 3, 2020

Online Published: August 7, 2020

doi:10.5430/ijhe.v9n7p176

URL: https://doi.org/10.5430/ijhe.v9n7p176

\begin{abstract}
The article has carried out a meta-analysis of the research concerning practice and innovations of inclusive education at school. Investigation of the practice of inclusive education at schools has been intensified since the 1990s, after identifying the need to implement inclusion strategies and concepts at the international level. The first studies of inclusive education (until the 2000s) concerned beliefs and values as a factor, influencing the effectiveness of inclusion, strategies of inclusive education. Investigations after the 2000s have been aimed at more focused subject matter of the research at the local level in different countries: principals' beliefs, teachers' self-efficacy, the role of parental support, school ideology, models of inclusion at private schools, the severity of disability as a factor determining teachers' beliefs concerning inclusion. Various inclusive models have been formed as a practice result of implementing inclusion. Two key effective approaches to integration of inclusion have been highlighted: integrated and differentiated. An integrated approach involves the introduction of innovations in inclusive education in the following elements of the educational system, namely: the concept (strategy) that defines the model, external preconditions and stages of inclusion; a school that defines the internal prerequisites for inclusion; a community. A differentiated approach is used in combination with theintegrated one in order to identify the internal prerequisites for inclusion: values, beliefs and attitudes of teachers, the competence of educators.
\end{abstract}

Keywords: inclusive, inclusive practices, school inclusive education, inclusive innovationю

\section{Introduction}

According to data of the Ministry of Education and Science of Ukraine, in 2016-2019 the number of inclusive classes has been increasing, as well as the number of students in such classes, and, accordingly, the number of teaching assistants is also growing.For comparison, in the 2016/2017 academic year the number of inclusive classes amounted 2715 units, in the 2018/2019 academic year - 8417 units; in the 2016/2017 academic year 4180 students received general secondary education, in the 2018/2019 academic year the number of students amounted 11866 . Accordingly, the number of teacher assistants in inclusive classes increased from 1825 to 7636 . "The number of secondary educational institutions with inclusive classes increased from 1518 to 3790" (Ministry of Education and Science of Ukraine, 2010). Such trends indicate the need to study the practice of inclusive education at schools and the necessary innovations to improve educational services for children with mental and physical disabilities. The current "Concept for the Development of Inclusive Education, approved by the Order of the Ministry of Education and Science of Ukraine dated October 1, 2010 No. 912" needs to be updated in accordance with new social changes 
(Ministry of Education and Science of Ukraine, 2010). The society, as a dynamic social-economic system, determines the transformation of education through innovations. The legal framework, developed in 2009-2015, needs to be updatedaccordingly to changingof social needs.Inclusive school reform is an important challenge for many governments around the world. In developed countries (Europe), discussions are being revolved around the inclusion strategy: "introduction of innovations in inclusive specialized education or introduction of inclusive innovations in general secondary education" (Vislie, 2003).

The relevance of the study is determined by the need to update the legal framework for inclusive education, the growth of students integrated into public schools and the society.As a consequence of these trends, a growing need arises to study the experience of EU countries in introducing innovations in inclusive education in the following areas: strategic, legal, educational (methods of teaching students, teachers'advanced studies), financial.

The purpose of the study is to examine the innovations of inclusive education at schools based on the generalization of the experience of EU countries in the implementation of different models of inclusive education.

The basic objectives of the study are defined the following ones:

1.Studying of EU statistics on the development of inclusive education at schools.

2.Formation of innovation of inclusive education at school depending on their direction: strategic, legal, educational (methods of training of pupils, advanced training of teachers), financial.

\section{Literature Review}

The accession of Ukraine to UN Declaration on Human Rights, UN Convention on the Rights of Persons with Disabilities, and the Rights of the Child has necessitated the development of state regulatory documents governing the implementation of the right to education for children with special educational needs.

The concept of inclusive education and special educational needs iscontroversial and varies from country to country in a narrower sense (disability) and broad sense (as a range of cognitive, physical, mental, behavioral needs of students). The definition of the essence of inclusive education is important because of the significant influence of teachers' beliefs on the effectiveness of inclusion, depending on special educational needs. Consequently, "the severity of disability changes teachers' perceptions of inclusion in favor of the less effective" (Avissar, Reiter \& Leyser, 2003).

The Law "On Education" (Verkhovna Rada of Ukraine, 2017) in Ukraine defines the basic terms: 1) "inclusive education is a system of educational services, guaranteed by the state and based on the principles of non-discrimination, consideration of human multifacetedness, effective involvement and involvement of all its participants in the educational process"; 2) inclusive educational environment is a set of conditions, methods and means of their implementation forcooperative learning, education and development of students, taking into account their needs and capabilities. Thus, in Ukraine the concept is considered in a broad sense, taking into account the mental and physical needs of all students.

Inclusive education is a process of comprehensive provision of equal access to high-quality education of children with special educational needs through the organization of education in general educational institutions, using individualized teaching methods and taking into account the educational and cognitive activities of children.

In order to ensure quality education, it is necessary to create safe, friendly, healthy and favorable learning conditions for students. The main principles of implementation of inclusive innovations should include: the partnership of school and community, integration of information and communication technologies, universal teaching methods. Important prerequisites for the effectiveness of inclusive education are the productivity and self-efficacy of teachers, communication competence of educators, a partnership approach to solving problems that arise in the learning process (Lancaster, 2014).

Another prerequisite for the introduction of inclusive education is "cultural values at school, which differ significantly around the world and determine the nature of inclusive education" (Corbett, 1999). The new organizational paradigm of education also depends on the values and beliefs of teachers, whicheventually determine their actions concerning implementing innovations in inclusive education (Carrington, 1999). A positive constructivist approach of teacherspromotes the effective implementation of inclusive innovations. The positive attitude and perception of inclusion by teachers depends on "the severity level of the disability and the educational environment (physical and mental support)" (Avramidis \& Norwich, 2002). The school principal is the leading person in introducing inclusion, whose vision and values influence on the inclusive educational process. "Beliefs and attitudes of teachers depend on age, qualifications, level of education, severity level of students' disabilities" 
(Avissar et al., 2003). These prerequisites primarily determine the social effects of inclusion, which exceed the effectiveness of inclusive education for students with special educational needs.

The importance of school ideology in inclusive educationis determined in the literature. Five models of ideology of private schools have been identified in the study of Göransson, Malmqvist and Nilholm (2013), depending on the inclusive educational process, in particular,a market-oriented-inclusive model and a holistic-inclusive model.

The effectiveness of inclusive education depends also on the attitude of students' parents without special educational needs.Recent investigations (Schmidt, Krivec \& Bastič, 2020) reveal that "parents of students with special educational needs are more open to inclusive education; theyrecognize the social effect of inclusive education and at the same time experience negative effects from students without special educational needs".

Modern models of inclusion include innovations in ensuring segregation (social, ethnic, migratory) of students to provide the most effective learning (Magnússon, 2020). Increasing dependence between the choice of school for the student and the growth of inequality is taking place. The inclusion of EU countries is characterized by the dependence of social-economic and migratory status and the possibility of choosing a school (Cooc \& Kiru, 2018). Innovation in the methods of inclusive education is being introduced: personification, differentiation and cooperation have become key aspects of inclusive education in EU countries (Paseka \& Schwab, 2020).

\section{Data and Methods}

The research is based on the conceptual theoretical and methodological principles of inclusive education, which have been highlighted in the investigations of Klemm (2018), Lindner, Alnahdi, Wahl and Schwab (2019), Magnússon (2020) and Schneider, Klemm, Kemper and Goldan. (2017). These publications are based on the secondary analysis of the inclusion features in EU countries, which are confirmed by statistical indicators and reflect the current major innovations of inclusive education.Therefore, the study is based on the concept of a combination of integrated and differentiated approaches.This means that inclusion is carried out, on the one hand, through the socialization of students at the public school, but, on the other hand, through the identification of students whose educational needs should be differentiated (personalization of students, their complex needs, use of different teaching methods, cooperation both with students and within the teaching staff).

Taking into consideration the concept of integration and differentiation, the study has been based on the following methods:

1) A meta-analysis of researches for the period of 1999-2020, assessing the effectiveness of inclusive education under the influence of internal and external factors. The principle of historicism has made it possible to identify the evolution of factors in the practice of inclusive education in different countries. Databases Google Scholar, Wiley Online, Elsevier, which contain publications for the period 1999-2020, have been used to conduct the secondary analysis.In particular, the search has been carried out by the following keywords: innovations of inclusion, inclusive education, inclusion at school, innovative teaching methods, models of inclusion in EU.Most investigations have been published in the followingscientific journals, namely: The Journal of Special Education, International Journal of Inclusive Education, European Journal of Special Needs Education, International Perspectives on Inclusive Education.

2) Comparative analysis has been applied to study differences in the practice of inclusive education in countries and regions.In particular, the following indicators from the database of the European Agency for Special Needs and Inclusive Education (n.d.) have been used:

1. The enrolment rate in mainstream education, based on the enrolled school population (\%) 2016/2017 academic year.

2. Age sample enrolment rate in inclusive education for 9-year-olds, based on the enrolled school population of 9-year-olds (\%).

3 Age sample enrolment rate in inclusive education for 15-year-olds, based on the enrolled school population of 15-year-olds (\%).

3) Legal analysis has been used to study the normative regulation of inclusive education in Ukraine.

4) Synthesis has been used to form internal and external determinants of inclusive education and the effectiveness of inclusive education' innovations from the perspective of an integrated and a differentiated approach.

Data for analysis were selected being based on the most common models of inclusion and their effectiveness, which has been proven in a number of studies of inclusive education in schools. Countries such as Greece, Germany, UK 
Sweden, Norway were chosen for the analysis. Their models of inclusive education are characterized by a number of features and most fully allow characterizing the types of inclusion in accordance with the EU experience.

\section{Results}

An integrated approach to inclusive school reforming is a central one to ensuring the success and potential development of general secondary schools. The comprehensiveness of the approach to inclusion is determined by the strategy of the country, which is the theoretical basis for choosing the model of inclusion and the goals of inclusion, the level of implementation of inclusion (local, state), special educational needs and mental and physical health of students, the values of the educational institution, the beliefs of teachers, providing continuing education for teachers and conducting trainings, modification of curricula and teaching methods, the attitude of the community and parents.

There are different approaches to inclusion and inclusive education models in countries. The model of complete inclusion has been applied in Italy at all educational levels for over 30 years, but the social and economic effects of inclusion have beenpoorly studied. In the study of Nepi, Facondini, Nucci and Peru (2013) concerning the effectiveness of the Italian inclusion model, it has been found that the complete inclusion model does not increase the social abilities of students with special educational needs. Such students try to ensure a deservedposition in the society, they are less perceived, and they are "more peripheral within the class and feel quite distant from their school". Another investigation (Zambelli \& Bonni, 2004) has showed that "holistic-inclusive model depends on the development of teachers' beliefs, which are formed through special education and training and can be a barrier to the implementation of inclusion". The importance of teachers' training during implementation of inclusion has been proven in the work of Egilson and Traustadottir (2009). The authors identify other factors of social effects of inclusion: parental support, curriculum modification, teachers' qualification (Egilson \& Traustadottir, 2009).

The total average enrolment rate in mainstream education in EU is $98,49 \%$ (Figure 1). Countries are characterized by the absence of differences in enrolment rate in mainstream education.

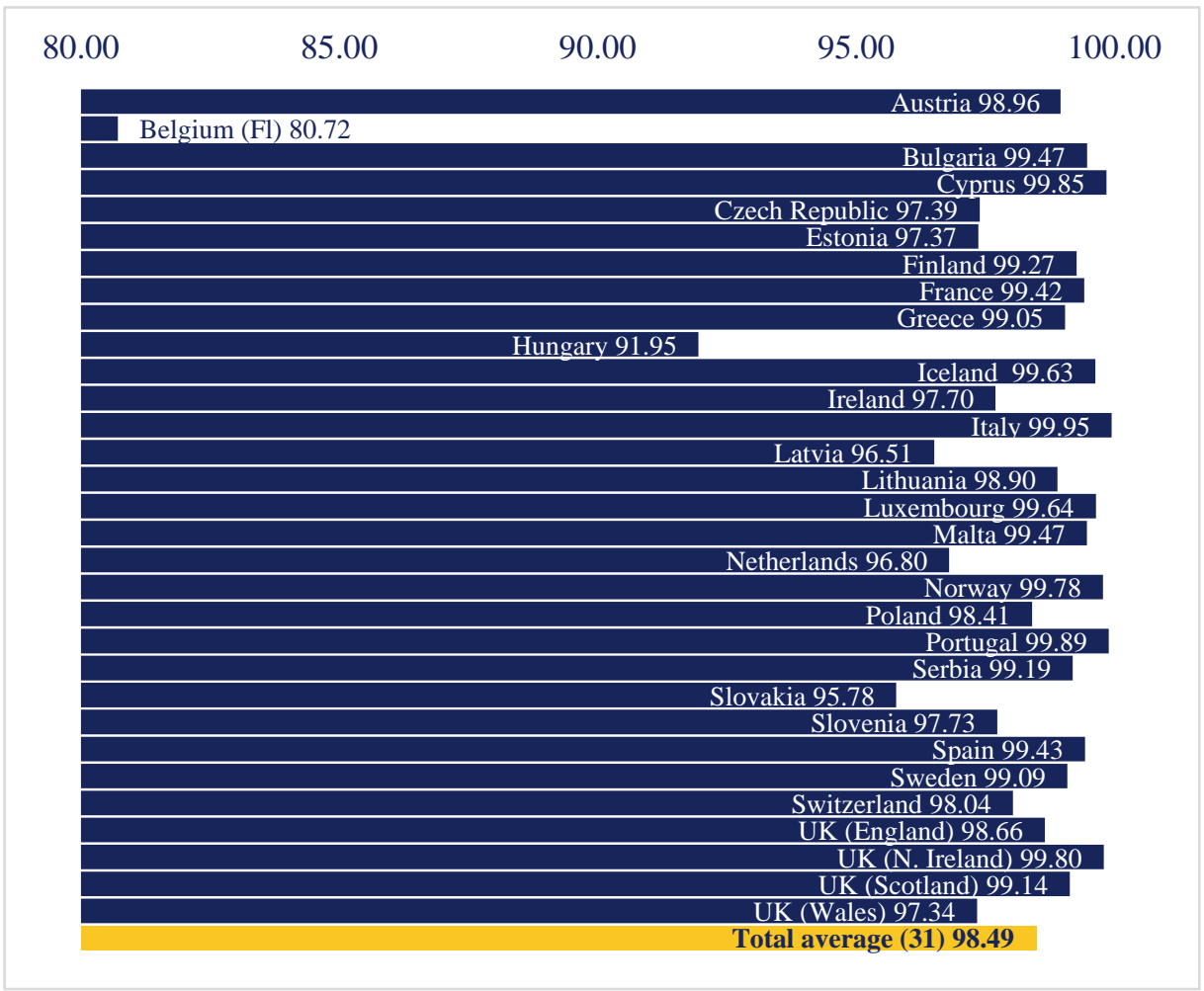

Figure 1. The enrolment rate in mainstream education, based on the enrolled school population (\%) 2016/2017 academic year

Source: European Agency for Special Needs and Inclusive Education (n.d.)

In most countries, "enrollment in mainstream education implies placement in a mainstream class, or placement in a separate special class within a mainstream school". Those learners, who are not in mainstream settings, are in fully separate special schools, non formal education run by health or social services, etc., or are out-of-school learners (European Agency for Special Needs and Inclusive Education, n.d.). 
The SEN identification rates range from $1,02 \%$ to $25,12 \%$; "the total average for the 31 countries is $4,75 \%$. The SEN identification rate for boys ranges from $0,55 \%$ to $15,28 \%$; the total average for the 29 countries is $3,18 \%$. The SEN identification rate for girls ranges from $0,47 \%$ to $9,84 \%$; the total average for the 29 countries is 1,55\%"(Figure 2 and Figure 3) (European Agency for Special Needs and Inclusive Education, n.d.).

The experience of primary general schools in Northern Greeceindicates"a positive attitude of teachers to inclusion in general, along with the variability of views depending on the severity of disability" (Avramidis \& Kalyva, 2007). The research, conducted by Avramidis and Kalyva (2007), also identifies more positive attitude of teachers at schools where curricula of inclusive education are actively implemented as opposed to inexperienced teachers.Long-term teachers' training (professional development courses) determines the beliefs of educators. Arthur-Kelly, Sutherland, Lyons, Macfarlane and Foreman (2013) prove the need to study the experience of teachers, who have been actively implementing inclusion and are characterized by more positive attitude towards inclusive education.

The experience of inclusion in Germany (Kiel, Braun, Muckenthaler, Heimlich, \& Weiss, 2019) indicates the "connection between teachers' self-efficacy and the effectiveness of inclusion implementation:the highest level of self-efficacy corresponds to the highest level of implementation of inclusive educational curricula". Types of self-efficacy also determine the state of implementation and cannot coexist. The self-efficacy of inclusive curriculato a greater extent determines the implementation of inclusion in contrast to the self-efficacy of cooperation.

The UK practice in inclusive education has its own characteristics: "the Special Educational Needs Code of Practice is applicable in the country, which defines the responsibility of teachers for the implementation of inclusion" (Cole, 2005). The experience of inclusive education in the UK suggests the need of re-thinking the role of Special Educational Needs Coordinator (SENCO). The main problems in the practice area of the person, responsible for inclusion,include:"the lack of time, funding, support, and the presence of operational responsibilities" (Cole, 2005). Studies of the views of primary school students in the UK (Adderley et al., 2015) indicate students' satisfaction with the educational process as a whole. The analysis has revealed the following basic problems of students, namely:"unfairness, shouting, loneliness and seating plans", which depend on the interpersonal relations of students and teachers. 


\section{$\begin{array}{llllll}50.00 & 60.00 & 70.00 & 80.00 & 90.00 & 100.00\end{array}$}

\section{Austria 99.09}

Belgium (Fl) 94.85

Bulgaria 99.57

Cyprus 95.41

Czech Republic 97.61

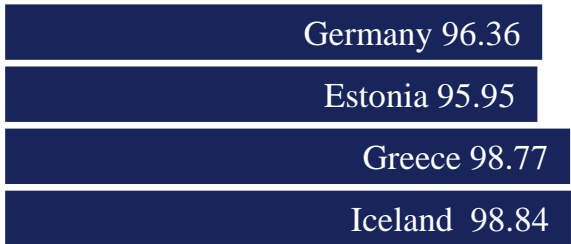

Italy 99.96

Lithuania 96.60

Luxembourg 99.32

Malta 99.90

Netherlands 97.86

Portugal 99.55

Slovakia 94.92

Slovenia 99.56

Spain 99.64

Switzerland 97.42

UK (England) 98.61

UK (N. Ireland) 97.71

UK (Scotland) 97.84

UK (Wales) 55.55

Total average (23) 97.84

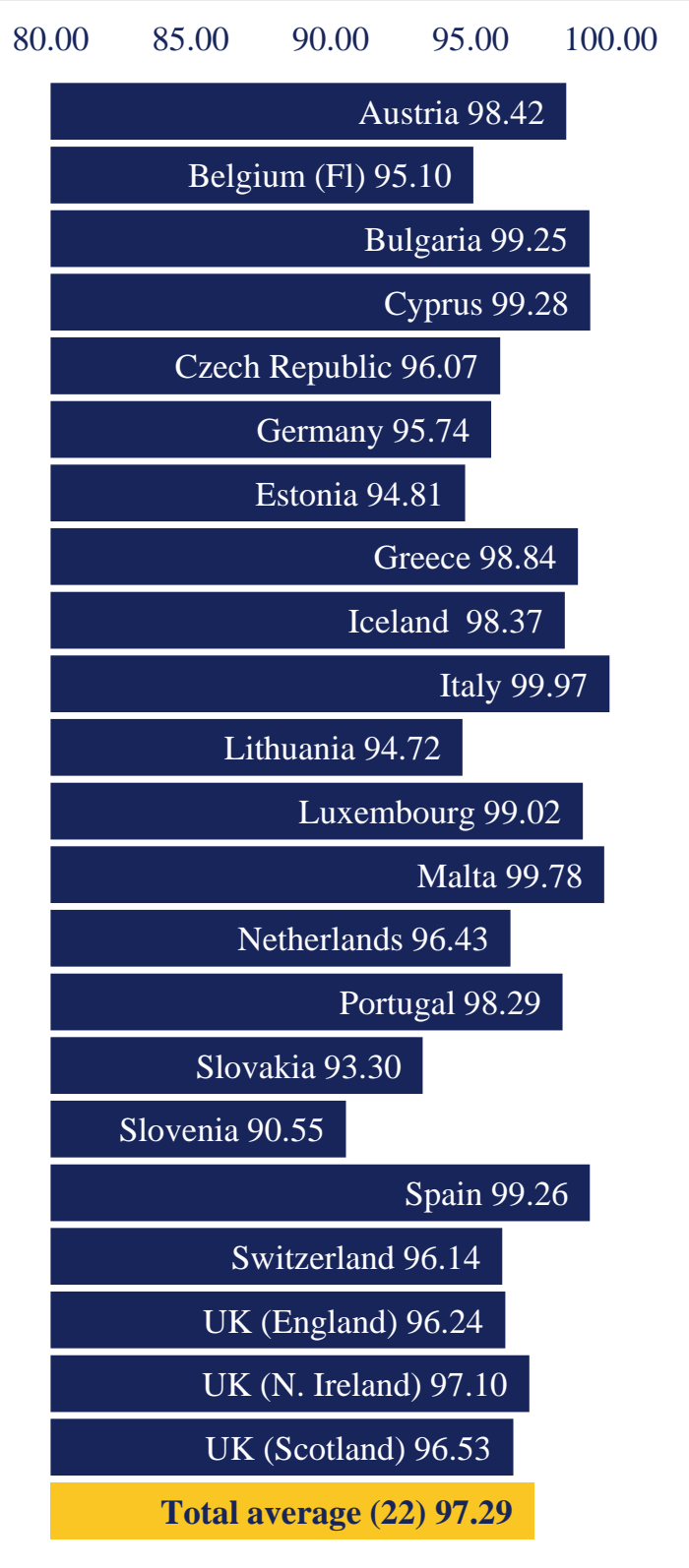

Figure 3. Age sample enrolment rate in inclusive education for 15-year-olds, based on the enrolled school population of 15 -year-olds (\%)

Source: European Agency for Special Needs and Inclusive Education (n.d).

Source: European Agency
Inclusive Education (n.d).

Needs and

In the UK, a teacher in the field of inclusive education and special educational needs, works with students who need additional support in training to ensure a full educational potential for them. Teaching is conducted in particular with children with physical, sensory, speech disorders, with general learning difficulties, specific learning difficulties (dyslexia), autism, social, emotional and mental needs, or a combination of these difficulties. Special educational needs (SEN) teacher can work in a mixed (inclusive) class, in a special class of a secondary school, at a special school for children with special educational needs, in a college; he can teach all students in the class, individual students or small groups who often have support from the teacher's assistant. A key aspect of the work of a special educational needs (SEN) teacher in this sphere is the identification of personal needs and responsibility for creating a safe, stimulating and conducive educational environment (Martinchuk, 2019b). Special educational needs (SEN) 
teacher should possess the most important skills for successful activities in an inclusive educational environment, such as: planning skills and organizational skills; ability to adapt to changed situations; ability to communicate effectively; behavior management skills and the ability to cope with complex behavior (Martinchuk, 2019b).

It is important to pay attention to the functional responsibilities of the special educational needs coordinator (head of the special educational needs department), which determine the possibility of teaching a student with special educational needs at a public school:

- management of SEN policy implementation and daily provision of students with special educational needs;

- coordination of work with different institutions and parents;

- collecting relevant information about children with special educational needs and providing special support to students who need the services of other educational, medical and social institutions.

Practical experience of Sweden, as a country, famous for the implementation of inclusive education, reveals"negative trends towards increased segmentation of students with special educational needs, basing on social-economic characteristics (especially migrants)" (Magnússon, 2020). Private schools are provided with less financial resources for ensuring inclusive education. The choice of school by students with special educational needs is limited.

Practical experience of inclusive education in Norway demonstrates that the solution of one of the main problems, arising in the process of integration, lies in the competence of teachers. In the 1990s, Norway set up a national program for the development of competences at schools. "This ensured systemic changes at schools and increasing the level ofteachers' competence" (Tangen, 2005).

Taking into consideration the importance of values, principles, beliefs and attitudes of teachers towards inclusion, an important task at the national level is to assess them prior implementing the inclusion practice. The study of teachers-practitioners of inclusive education is important for the formation of a positive attitude of teachers who do not have such experience.

Differentiation of inclusive models should take place at the local level based on the mental and physical characteristics of students with different educational needs. The severity of disability is a factor in the success of inclusion, as well as the choice of an inclusive model, and the teacher's curriculum for introducing inclusion. The severity of disability also determines the social effects of inclusion.

The effective practice of inclusive education depends on educational strategies, organization, planning and the educational process, ensuring the adaptation of students with special educational needs. "Differentiation of educational processes forms a research space at school" (Fernández-Batanero, 2014). All interested parties should participate in an inclusive educational process. "The mission and vision of inclusion determines the effectiveness of inclusive programs" (Nicolaidou, Sophocleous \& Phtiaka, 2006).

In order to implement inclusion at school's practice, innovations should be introduced into personnel policy: teacher training, professional development, competence development, in particular the ability to personalize the educational needs of students. Teachers should accept and understand the new educational paradigm, new ways of organizing the educational process, development of educational and methodological support, master modern methods of differentiated and personality-oriented teaching (depending on the individual needs of the student) (Kolupaeva \& Taranchenko, 2016).

The complexity of implementing innovations and their perception by teachers depends on several factors:

1) lack of understanding of the importance of innovation and the value of innovation by teachers;

2) lack of skills and competences of teachers, awareness of the benefits of innovation;

3) lack of confidence in highly qualified training for working with children with special educational needs;

4) lack of an effective mechanism for diagnosing students with special educational needs: the ability to identify the complexity of mental and physiological needs of the student, which determines the possibility of her ability to study in an inclusive classroom with additional support of the assistant;

5) lack of resources: human resources (Klemm, 2018); educational and methodical and special resources (Schneider et al., 2017);

6) insufficient development of inclusive culture, policies and lack of inclusive practices.

Teachers should ensure the partial organization of inclusion at the school in three directions: inclusive culture; inclusive policy; inclusive practices.Inclusive culture is understood as the formation of a trusting environment, the 
establishment of values of inclusion.Inclusive policy is the organization of supporting diversity in student's education through the use of numerous teaching methods by teachers. In order to ensure inclusive policy, it is necessary to introduce innovations into the educational process: new interactive teaching methods, development of teachers' competences. Inclusive practices are the organization of training and mobilization of resources in order to create a favorable place for study and recreation (providing technical equipment and an acceptable class space).

\section{Discussion}

Recent investigations give evidence of the fact that the use of a variety of inclusive methods, differentiation and personalization of methods contribute to a more positive attitude of teachers to inclusive education. The teacher's intervention and support should diagnose a child's readiness to study in an inclusive classroom.Intervention and support should be provided at the first stage: in case of choosing a school or, in the event of learning difficulties: first in the form of support by the class teacher.If this is not enough, support should be provided by a special education teacher, who usually works at a secondary school. The most common form of support for a child with special educational needs at school is "the pull-out model" (Martinchuk, 2019b). This form involves visiting a special education teacher's room during certain lessons. At the same time, there is a problem of devaluation of such support, which further affects the success of learning and inclusion. However, if a student has significant learning difficulties, he or she may be offered special full-time education (that is, in a special educational institution).

Resources of inclusive education are divided into personnel (teaching and non-teaching staff) andteaching-learning materials and special resources (Schneider et al., 2017). Accordingly, inclusive culture, inclusive policies and inclusive practices can be considered as resources in inclusive education. As a rule, the main obstacle to successful inclusion's implementation is the lack of resources, including human resources, that meet the specific educational needs of students. The amount of resources and flexibility in their use of available resources in Europe varies greatly. However, the success of inclusive education requires competent human resources.Germany allows schools to refuse a student's admission in case of absence of human resources (Klemm, 2018). The availability of resources and the level of provision of human resources determines the level of perception of inclusive education by teachers: a high level of positive attitude is connected with a high level of provision of personnel.

Differentiation of innovations of inclusive education determines the effectiveness of its implementation.Practice of implementing inclusion proves the need for a differentiated approach to innovations.

The strategy and policy of inclusion implementation should be developed in accordance with international practice and cultural and social characteristics of students of the country, region, school. The application of the most effective practices of countries where inclusion is actively implemented is advisable, taking into account a number of factors of the country where the implementation takes place. Curricula should be modified and integrated into the educational process of general secondary schools.

The social effects of inclusive education have been proven by the practice of inclusion in developed countries. Among the positive social effects, it is worth highlighting the provision of the social position of students with special educational needs, the formation of a positive attitude towards the integration of students with special educational needs in the society.

European countries face similar systemic problems of inclusive education. Problem solving is legislative in nature; it is implemented at the state level through the application of national strategies and programs of inclusive education, programs for improving teachers' competences.

Traditional Western models of inclusive education, adopted around the worldto a different extent, adapt to an inclusive approach. Similar trends are observed in the inclusive education system, legislative changes are introduced by the Ministry of Education and Science of Ukraine (2010) and NGOs that implement inclusive education in the Ukrainian educational space. Such trends, observed everywhere, are probably due to the fact that the models of education that are currently used have never been designed in such a way as to primarily cover all students. From the very beginning, schools were created as elite institutions for those who could afford to attend them or whose abilities were well suited for acquiring the material. To some extent, they currently remainin such condition. The special education system was created on the basis of a number of reasons, but children with disabilities, children with special educational needs without disabilities remained outside the elite educational context. This does not mean that professionals with the best intentions neither created nor worked in the system of special education; they currently have been working there; most likely the prerequisite for special education is segregation, regardless of whether it is based on the idea of providing more appropriate education or protecting marginalized groups from the realities of secondary schools (Martinchuk, 2019a). 
In Ukraine, inclusive pedagogy / pedagogy of inclusive education is a relatively young branch of pedagogical knowledge, which, in fact, began to develop after the country had gained independence as a result of increasing public demand for theory and methods of teaching and educating children with various special educational needs in terms of educational inclusion and training of teachers to work with such children in an inclusive educational environment.

\section{Conclusion}

A meta-analysis of studies of the practice and innovations of inclusive education at schoolgives grounds to formulate a number of important conclusions. Investigation of the practice of inclusive education at schools has been intensified since the 1990s, after identifying the need to implement inclusion strategies and concepts of inclusive education at the international level. The first studies of inclusive education (until the 2000s) have concerned beliefs and values as a factor, influencing the effectiveness of inclusion, strategies of inclusive education. Investigations after the 2000s have been aimed at more focused subject matter of the research at the local level in different countries: principals' beliefs, teachers' self-efficacy, the role of parental support, school ideology, models of inclusion at private schools, the severity of disability as a factor determining teachers' beliefs concerning inclusion. As a result, various models of inclusion have been studied on the basis of effective practice of introducing innovations into the educational process. Two key effective approaches to integration of inclusion have been highlighted: integrated and differentiated, which complement each other depending on regional differences in inclusive education. Regional differences in inclusion are in turn determined by the complexity of the special educational needs of students, the number of students with particularly complex educational needs and the availability of teachers who can work with such students. An integrated approach provides the introduction of innovations in inclusive education in the following elements of the educational system, namely: the concept (strategy) that defines the model, external preconditions and stages of inclusion; a school that defines the internal prerequisites for inclusion; a community. A differentiated approach is used in combination with the integrated one in order to identify the internal prerequisites for inclusion: values, beliefs and attitudes of teachers, the competence of educators.

\section{References}

Adderley, R. J., Hope, M.A., Hughes, G.C., Jones, L., Kyriaki Messiou, K., \& Shaw P.A. (2015). Exploring inclusive practices in primary schools: focusing on children's voices. European Journal of Special Needs Education, 30(1), 106-121. https://doi.org/10.1080/08856257.2014.964580

Arthur-Kelly, M., Sutherland, D., Lyons, G., Macfarlane, S., \& Foreman, P. (2013). Reflections on enhancing pre-service teacher education programmes to support inclusion: perspectives from New Zealand and Australia. European Journal of Special Needs Education, 28(2), 217-233. https://doi.org/10.1080/08856257.2013.778113

Avissar, G., Reiter, S., \& Leyser, Yo. (2003). Principals' views and practices regarding inclusion: the case of Israeli elementary school principals. European Journal of Special Needs Education, 18(3), 355-369. https://doi.org/10.1080/0885625032000120233

Avramidis, E., \& Kalyva, E. (2007). The influence of teaching experience and professional development on Greek teachers' attitudes towards inclusion. European Journal of Special Needs Education, 22(4), 367-389. https://doi.org/10.1080/08856250701649989

Avramidis, E., \& Norwich, B. (2002). Teachers' attitudes towards integration / inclusion: a review of the literature. European Journal of Special Needs Education, 17(2), 129-147. https://doi.org/10.1080/08856250210129056

Carrington, S. (1999). Inclusion needs a different school culture. International Journal of Inclusive Education, 3(3), 257-268. https://doi.org/10.1080/136031199285039

Cole, B. A. (2005). Mission impossible? Special educational needs, inclusion and the re conceptualization of the role of the SENCO in England and Wales. European Journal of Special Needs Education, 20(3), 287-307. https://doi.org/10.1080/08856250500156020

Cooc, N., \& Kiru., E. W. (2018). Disproportionality in special education: A synthesis of international research and trends. The Journal of Special Education, 52(3), 163-173. https://doi.org/10.1177/0022466918772300

Corbett, J. (1999). Inclusive education and school culture. International Journal of Inclusive Education, 3(1), 53-61. https://doi.org/10.1080/136031199285183

Egilson, S. T., \& Traustadottir, R. (2009). Assistance to pupils with physical disabilities in regular schools: promoting inclusion or creating dependency? European Journal of Special Needs Education, 24(1), 21-36. D https://doi.org/10.1080/08856250802596766 
European Agency for Special Needs and Inclusive Education. (n.d.). European Agency Statistics on Inclusive Education: 2018 Dataset Cross-Country Report. Retrieved from https://www.european-agency.org/resources/publications/european-agency-statistics-inclusive-education-2018-d ataset-cross-country

Fernández-Batanero, J. M. (2014). Strategies for inclusion in the face of social exclusion. Case study in Andalusia (Spain). European Journal of Special Needs Education, 29(3), $415-428$. https://doi.org/10.1080/08856257.2014.906978

Göransson, K., Malmqvist, J., \& Nilholm, C. (2013). Local school ideologies and inclusion: the case of Swedish independent schools. European Journal of Special Needs Education, 28(1), 49-63. https://doi.org/10.1080/08856257.2012.743730

Kiel, E., Braun, A., Muckenthaler, M., Heimlich, U., \& Weiss, S. (2019). Self-efficacy of teachers in inclusive classes. How do teachers with different self-efficacy beliefs differ in implementing inclusion? European Journal of Special Needs Education. https://doi.org/10.1080/08856257.2019.1683685

Klemm, K. (2018). Unterwegs Zur Inklusiven Schule [on the Way to Inclusive Schools]. Gütersloh: Bertelsmann Stiftung. $\quad$ Retrieved from http://www.bertelsmann-stiftung.de/fileadmin/files/BSt/Publikationen/GrauePublikationen/Studie_IB_Unterwe gs-zur-inklusiven-Schule_2018.pdf

Kolupaeva, A. A, \& Taranchenko, O. M. (2016). Inclusive education: from basics to practice: monograph. Kyiv, Ukraine: ATOPOL.

Lancaster, J. (2014). School and classroom indicators of inclusive education. Measuring Inclusive Education (International Perspectives on Inclusive $\quad$ Education), $227-245$. https://doi.org/10.1108/S1479-363620140000003027

Lindner, K. T., Alnahdi, G. H., Wahl, S., \& Schwab, S. (2019). Perceived differentiation and personalization teaching approaches in inclusive classrooms: Perspectives of students and teachers. Frontiers in Education, 4, Article 58. https://doi.org/10.3389/feduc.2019.00058

Magnússon, G. (2020). Inclusive education and school choice lessons from Sweden. European Journal of Special Needs Education, 35(1), 25-39, https://doi.org/10.1080/08856257.2019.1603601

Martinchuk, O. V. (2019a). Inclusive pedagogy as a scientific factor in the formation of competence in the field of inclusive education of children with special educational needs. Current issues of correctional education (pedagogical sciences): collection of scientific works, $13, \quad 157-175$. https://doi.org/10.32626/2413-2578.2019-13.157-175

Martinchuk, O. V. (2019b). Professional activity of special teachers of inclusive educational institutions in countries with a high level of development of educational systems (on the example of Great Britain, Finland and Israel). Current issues of correctional education (pedagogical sciences): collection of scientific works, 12. Retrieved from

http://aqce.com.ua/vipusk-n12-2019/professional-activity-of-special-teachers-of-inclusive-educational-institutio ns.html

Ministry of Education and Science of Ukraine. (2010). About approval of the Concept of development of inclusive training.

Retrieved

from https://mon.gov.ua/ua/npa/pro-zatverdzhennya-kontseptsii-rozvitku-inklyuzivnogo-navchannya

Nepi, L. D., Facondini, R., Nucci, F., \& Peru, A. (2013). Evidence from full-inclusion model: the social position and sense of belonging of students with special educational needs and their peers in Italian primary school. European Journal of Special Needs Education, 28(3), 319-332. https://doi.org/10.1080/08856257.2013.777530

Nicolaidou, M., Sophocleous, A., \& Phtiaka, H. (2006). Promoting inclusive practices in primary schools in Cyprus: empowering pupils to build supportive networks. European Journal of Special Needs Education, 21(3), 251-267. https://doi.org/10.1080/08856250600810666

Paseka, A., \& Schwab, S. (2020). Parents' attitudes towards inclusive education and their perceptions of inclusive teaching practices and resources. European Journal of Special Needs Education, 35(2), $254-272$. https://doi.org/10.1080/08856257.2019.1665232

Schmidt, M., Krivec, K., \& Bastič, M. (2020). Attitudes of Slovenian parents towards pre-school inclusion. 
European Journal of Special Needs Education. https://doi.org/10.1080/08856257.2020.1748430

Schneider, K., Klemm, K., Kemper, T., \& Goldan, J. (2017). Dritter Bericht Zur Evaluation Des Gesetzes Zur Förderung Kommunaler Aufwendungen Für Die Schulische Inklusion in Nordrhein-Westfalen [Third report on the evaluation of the law to promote municipal expenses for school inclusion in North Rhine-Westphalia]. Retrieved from http://www.wib.uni-wuppertal.de/forschung/projekte/evaluation-kommunaler-aufwendungen-fuer-die-schulisch e-inklusion.html

Tangen, R. (2005). Promoting inclusive education in secondary school in Norway: a national programme for teacher development. European Journal of Special Needs Education, 20(1), 57-70. https://doi.org/10.1080/0885625042000319089

Verkhovna Rada of Ukraine. (2017). On Education. Retrieved from https://zakon.rada.gov.ua/laws/show/2145-19

Vislie, L. (2003). From integration to inclusion: focusing global trends and changes in the western European societies. European Journal of Special Needs Education, 18(1), 17-35. https://doi.org/10.1080/0885625082000042294

Zambelli, F., \& Bonni, R. (2004). Beliefs of teachers in Italian schools concerning the inclusion of disabled students: a Qsort analysis. European Journal of Special Needs Education, 19(3), 351-366. https://doi.org/10.1080/0885625042000262505 